\title{
INFILTRACIÓN PLEURAL EN LA RECAÍDA DE UN MIELOMA MÚLTIPLE
}

\author{
Pleural infiltration in a relapse of multiple myeloma
}

Joud Zanabili Al-Sibaia ${ }^{1}$, Laura Francisca Ávila Idrovo ${ }^{1}$, Eduardo Higueras Mora ${ }^{1}$, Sara Alonso Álvarez ${ }^{1}$, Sana Shehadeh Mahmalatc ${ }^{2}$

1. Hospital Universitario Central de Asturias España Email de contacto: joudzas88@gmail.com

2. Hospital Vital Álvarez Buylla España

El mieloma múltiple (MM) es la segunda neoplasia hematológica maligna más frecuente y se presenta generalmente con dolor óseo, fracturas patológicas y anemia ${ }^{1}$. Puede afectar al tórax en forma de lesiones óseas, plasmocitomas, infiltraciones pulmonares y derrame pleural $^{2}$. Si bien el derrame pleural se observa en el $6 \%$ de pacientes con mieloma ${ }^{3}$, el derrame pleural por infiltración de células plasmáticas es poco frecuente, con una incidencia del $0,8 \%$ y menos de 100 casos descritos hasta la fecha.

A un varón de 60 años se le diagnosticó de mieloma múltiple IgA lambda con plasmocitoma extraóseo supraclavicular en enero de 2016. Se trató con inicialmente con ciclos de VRD (bortezomib, lenalidomida y dexametasona), tras el $3^{\circ}$ ciclo se constató progresión extramedular con adenopatías axilar, supraclavicular y cervical derecho a las que se realizó una biopsia con aguja gruesa detectándose por citogenética hiperploidía con $t(14 ; 16)$ en el $90 \%$ de los núcleos. Recibió posteriormente tratamiento con 2 ciclos de VRD-PACE (VRD-cisplatino, adriamicina, ciclofosfamida y etopésido) y radioterapia en los plasmocitomas, alcanzando remisión completa estricta. En junio de 2016, se le realizó un trasplante autólogo de progenitores hematopoyéticos.

Se presentó en septiembre de 2016 con dolor torácico derecho de carácter pleurítico, disnea y astenia. La radiografía de tórax mostró derrame pleural (Fig. 1, flecha) y atelectasia pasiva de los lóbulos medio e inferior derechos.

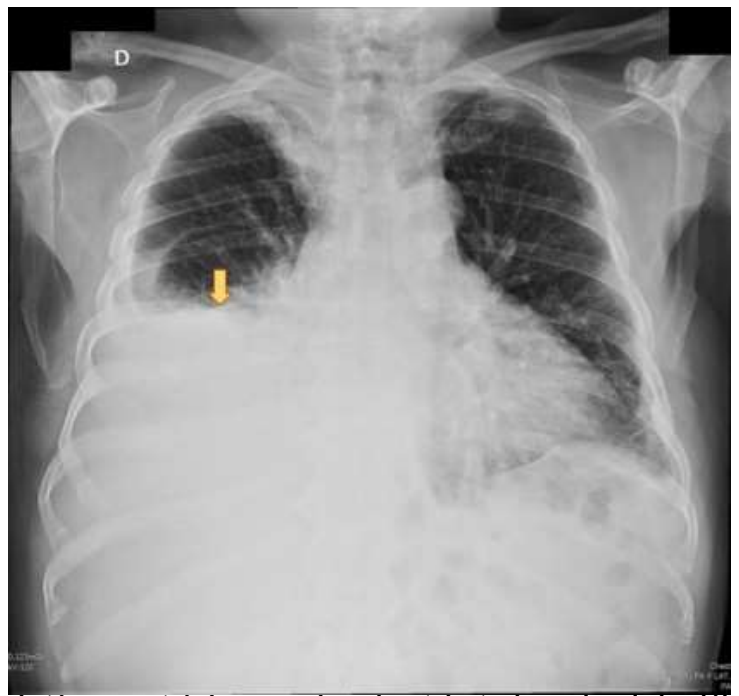

Figura 1: flecha La radiografía de tórax mostró derrame pleural y atelectasia pasiva de los lóbulos medio e inferior derechos 
Los resultados de las pruebas de laboratorio fueron: hemoglobina $8,8 \mathrm{~g} / \mathrm{dl}$, leucocitos $1,71 \times 10^{9} / \mathrm{L}$, plaquetas $19 \times 10^{9} / \mathrm{L}$, creatinina $1,31 \mathrm{mg} / \mathrm{dl}$, acido úrico $11,1 \mathrm{mg} / \mathrm{dl}$, calcio $2,35 \mathrm{mmol} / \mathrm{L}$, proteína total $8,1 \mathrm{~g} / \mathrm{dl}$ y albúmina $3,4 \mathrm{~g} / \mathrm{dl}$, ß-2 microglobulina $4,2 \mathrm{mg} / \mathrm{L}$. El frotis de sangre periférica mostró un $8 \%$ de células plasmáticas (Fig.2, la flecha indica una célula plasmática binucleada en sangre periférica).

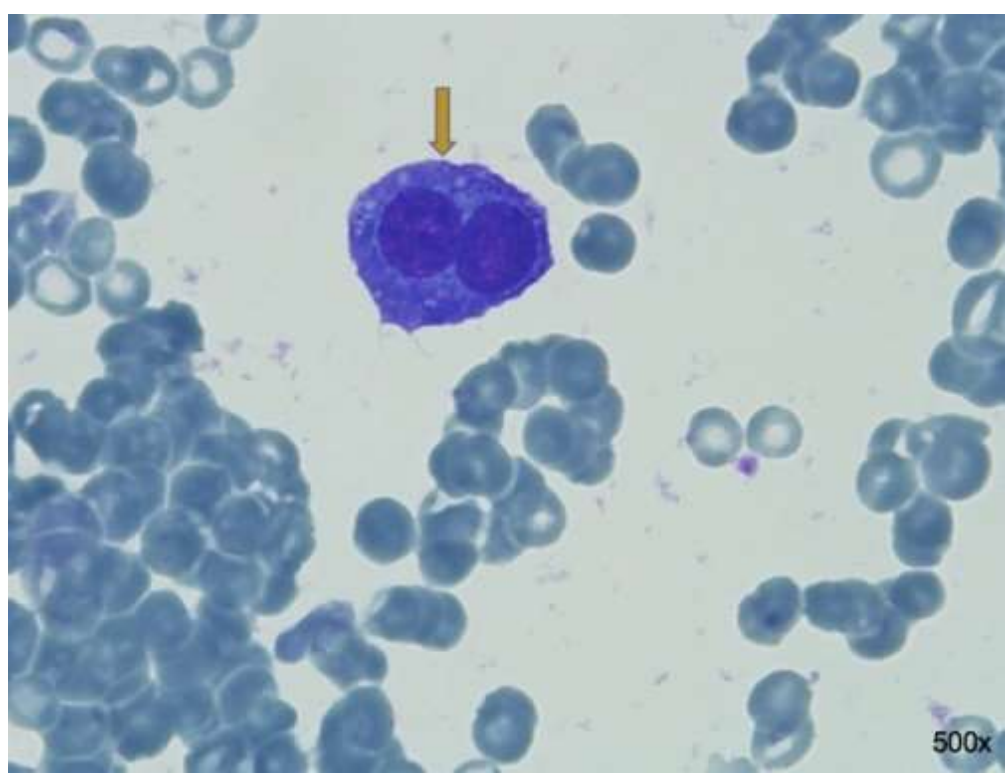

Figura 2: la flecha indica una célula plasmática binucleada en sangre periférica

Constatándose una recaída precoz en forma de leucemia de células plasmáticas.

Se realizó toracocentesis que reveló exudado con $5,6 \mathrm{~g} / \mathrm{dL}$ de proteína (ratio LDH líquido pleural/suero de 1.4 y ratio de proteínas líquido pleural/suero de 0.8 ). El examen citológico del líquido mostró numerosas células plasmáticas, se observaron múltiples células plasmáticas binucleadas (Fig. 3, estrellas) y otras con inclusiones intracitoplasmáticas (Fig. 3, flechas)

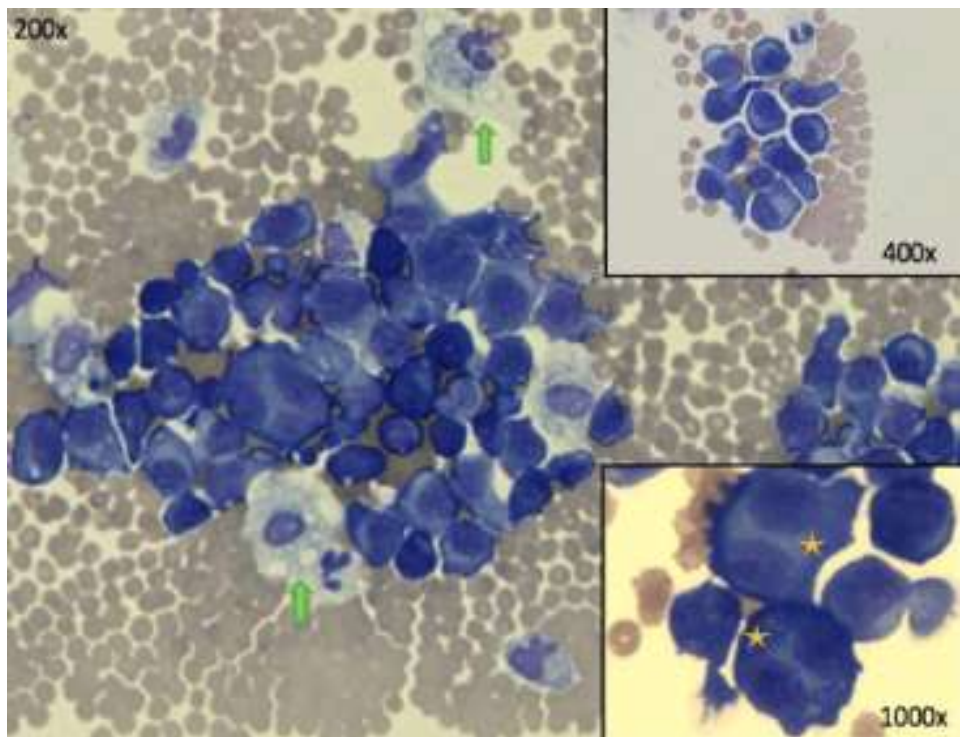

Figura 3: (estrellas) células plasmáticas binucleadas y otras con inclusiones intracitoplasmáticas ver Figura 3: (flechas) 
La citometría de flujo demostró un inmunofenotipo patológico de las células plasmáticas encontradas en el líquido pleural (cyLambda+ CD38+CD138+), al igual que se detectó traslocación (14;16) por hibridación fluorescente "in situ" (FISH) (Fig.4).

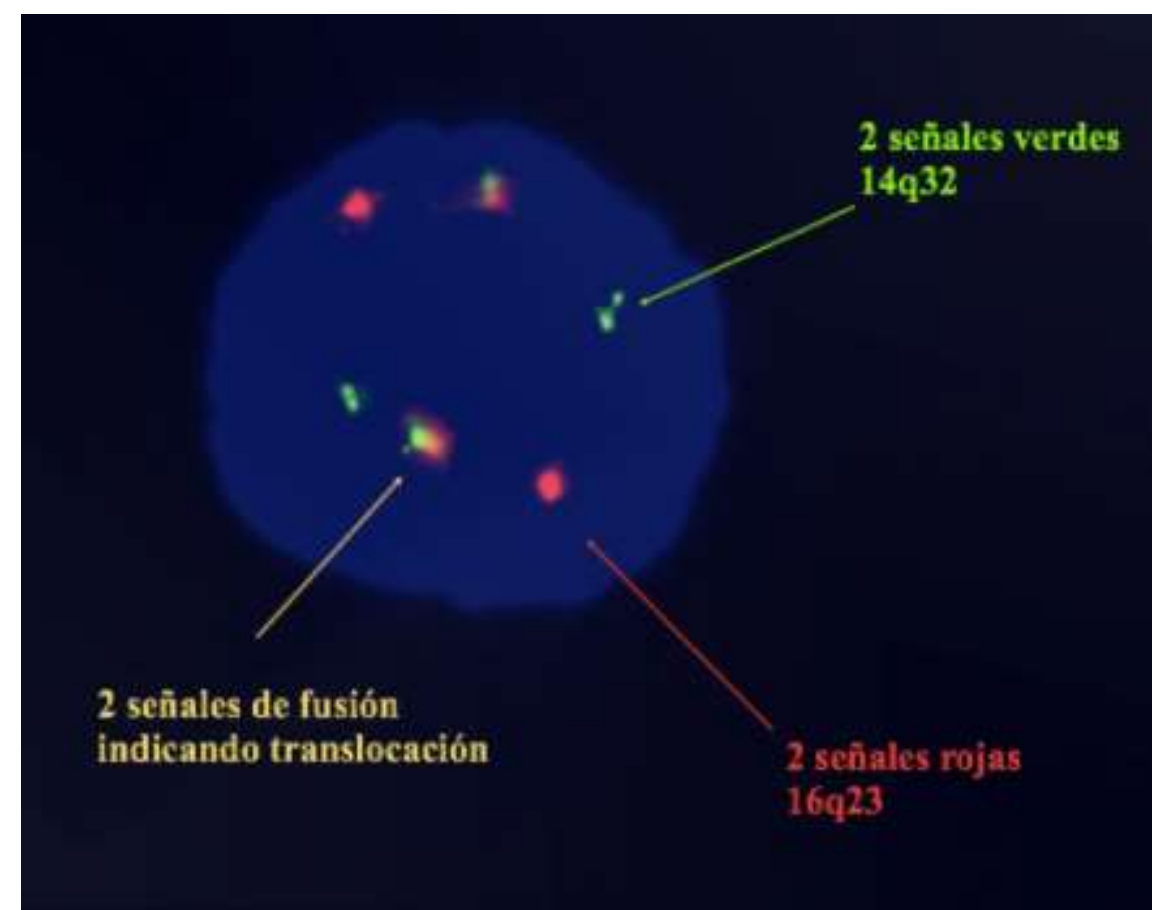

Figura 4: La citometría de flujo demostró un inmunofenotipo patológico de las células plasmáticas encontradas en el líquido pleural (cyLambda+ CD38+ CD138+), al igual que se detectó traslocación (14;16) por hibridación fluorescente "in situ" (FISH)

Se añadió tratamiento con pomalidomida, pero el paciente falleció por insuficiencia respiratoria 2 meses tras el diagnóstico de afectación pleural.

Los criterios de diagnóstico del derrame pleural mielomatoso son: hallazgo de una proteína monoclonal por electroforesis del líquido pleural, detección de células plasmáticas atípicas en el líquido pleural y confirmación histológica por biopsia pleural ${ }^{4}$. Por otra parte, la translocación del gen IGH en el cromosoma 14 con el gen MAF en el cromosoma 16 se ha descrito entre el $5-7 \%$ de los casos. Los pacientes con la $\mathrm{t}(14 ; 16)$ tienen mal pronóstico, una clínica más agresiva y, a diferencia de otros subgrupos moleculares, su resultado no mejora con la introducción de bortezomib. $^{5}$

\section{Bibliografía}

1. Smith A, Howell D, Patmore R, Jack A, Roman E. Incidence of haematological malignancy by sub-type: A report from the Haematological Malignancy Research Network. Br J Cancer. 2011;105:1684-92.

2. Oudart JB, Maquart FX, Semouma O, Lauer M, Arthuis-Demoulin P, Ramont L. Pleural effusion in a patient with multiple myeloma. Clin Chem. 2012;58:4672-6.

3. Rodríguez JN, Pereira A, Martínez JC, Conde J, Pujol E. Pleural effusion in multiple myeloma. Chest. 1994;105:622-4.

4. Varettoni M, Corso A, Pica G, Mangiacavalli S, Pascutto C, Lazzarino M. Incidence, presenting features and outcome of extramedullary disease in multiple myeloma: A longitudinal study on 1003 consecutive patients. Ann Oncol. 2010;21:325-30. 5. Qiang Y-W, Ye S, Chen Y, et al. MAF protein mediates innate resistance to proteasome inhibition therapy in multiple myeloma. Blood. 2016;128(25):2919 LP-2930. 